\title{
Antioxidant and Total Phenolic Content of Breadfruit (Artocarpus altilis) Leaves
}

\author{
Lee Yit Leng ${ }^{l, a}$, Nuramira binti Nadzril, ${ }^{1, b}$ Khor Chu Yee ${ }^{1, c}$, Norawanis binti Abdul Razak ${ }^{1, d}$ and Abdul Razak Shaari ${ }^{1, e}$ \\ ${ }^{1}$ Faculty of Engineering Technology, Universiti Malaysia Perlis (UniMAP), Campus of UniCITI Alam Sungai Chuchuh, Padang \\ Besar, 02100 Perlis, Malaysia.
}

\begin{abstract}
This work aims to determine antioxidant, total phenolic content and Fourier transform infrared spectroscopy (FTIR) analysis of breadfruit leaves which are essential in management of diabetes. The methanolic extracts of breadfruit leaves was used to analyze for total phenolic content and antioxidant. Total phenolic content of the extracts was measured using the Folin-Ciocalteu assay while the antioxidant activity of plant extracts was measured by the 1, 1-diphenyl-2-picryhyradrazyl (DPPH) radical scavenging assay. FTIR analysis was used to determine the chemical components in the leaves. Total phenolic content in fresh breadfruit leaves $(144.16 \mathrm{mg} / \mathrm{g} \pm 17.98)$ was comparable to those of green tea. The results showed the breadfruit leaves extracts exhibited potent antioxidant activity. The presence of $\mathrm{OH}$ group also suggests antioxidant capacity of breadfruit leaves to deactivate free radicals as glucose itself could react with hydrogen peroxide in the presence of iron and copper ions to form hydroxyl radical.
\end{abstract}

\section{Introduction}

Antioxidant is a bioactive compound that protects a biological target against oxidative damage [1]. Antioxidant prevents the formation of reactive species like peroxides or hydrogen peroxide $\left(\mathrm{H}_{2} \mathrm{O}_{2}\right)$, deactivate free radicals by capturing free radicals and repair damage at once happened in our bodies. Phenolic nutraceuticals have been suggested as effective antioxidants related to health promotion [2].

Numerous studies have been reported on useful of phenolic compounds in exhibiting potential biological activities such as antioxidant, anti-diabetic, antimicrobial and anticancer [3]. The phenolic compounds from several plant sources have been shown to inhibit aamylase and a-glucosidase activities and allow for better control of blood glucose levels. Management of diabetes without any side effects is still a challenge to the medical system [4]. Diabetes mellitus is a chronic disease caused by inherited and/or acquired deficiency in the production of insulin by the pancreas, or by the ineffectiveness of the insulin produced. Such a deficiency results in increased concentrations of glucose in the blood, which in turn damage many of the body's systems, in particular the blood vessels and nerves.

Herbal drugs are widely prescribed because of their effectiveness, lack side effects and relatively low cost. Ample bioactive compounds which derived from plants are potential to establish antidiabetic activity. Green, yellow and black tea leaves are generally rich in phenolic compounds [5].
Breadfruit (Artocarpus altilis) is a staple food and traditional crop originating in the South Pacific and is now been cultivated widely in tropics. It has been recognized for its potential to prevent hunger in the tropics and developing countries [6]. Some findings suggest that traditional diet based on breadfruit can prevent onset of type II diabetes [7][8] based on field observations, ethnobotanical reports and medical records. All parts of the breadfruit trees are used medicinally, especially the leaves.

Breadfruit leaves are characterized with a pleasing flavor. The leaves of breadfruit have also been consumed by some local people to reduce the glucose level in body. However, there is not much information on the antioxidant capacity and total phenolic content from the breadfruit leaves in regulating blood glucose levels. This study was carried out to determine antioxidant, total phenolic contents and FTIR analysis of breadfruit leaves which are essential in management of diabetes.

\section{Materials and Methods}

\subsection{Samples Collection and Preparation}

About $500 \mathrm{~g}$ of fresh breadfruit leaves were collected from Perlis, northern part of Malaysia. The leaves were thoroughly cleaned with distilled water prior to extraction. The cleaning process is important to get rid of unwanted substances. The leaves were separated from their petioles.

\footnotetext{
* Corresponding author: yllee@unimap.edu.my
} 


\subsection{Plant Extraction}

After the preparation of fresh leaves, the leaves were ground into powder using a blender. About $0.2 \mathrm{~g}$ powders were put into conical flask and $20 \mathrm{ml}$ methanol was added. The mixture was placed in water bath at $40^{\circ} \mathrm{C}$ for 3 hours. Afterwards, the sample was filtered using filter paper. The extract was stored in a cap bottle at $4{ }^{\circ} \mathrm{C}$ for further analysis.

\subsection{Antioxidant Analysis}

The 1, 1-diphenyl-2-picryhyradrazyl (DPPH) radical scavenging assay is a standard procedure to determine the antioxidant activity of plant extracts and natural compounds. The free radical scavenging activity of methanolic leaf extract was measured using the method described by Cos et al. (1998) [9].

About $2 \mathrm{ml}$ of methanolic DPPH solution was added to $200 \mu 1$ of water extract of leaves and then was added with methanol to make final volume of $3 \mathrm{ml}$. After 60 min, the absorbance was measured against methanol as a blank at $517 \mathrm{~nm}$ using spectrophotometer [10]. The free radical scavenging activities of the tested samples were compared with a control. Percentage inhibition of the DPPH radicals was calculated using the formula below:

Percent of inhibition $(\%)=\left[\frac{\text { Ac of control }- \text { As of sample }}{\text { Ac of control }}\right] \times 100$

$\mathrm{Ac}=$ The absorbance of control

As $=$ The absorbance of sample

\subsection{Total Phenolic Content Determination}

Total phenolic contents of the extracts were measured using the Folin-Ciocalteu assay developed by Singleton and Rossi (1965) [11]. About $0.5 \mathrm{~mL}$ of samples was pipetted into $10 \mathrm{~mL}$ volumetric flask containing $0.5 \mathrm{~mL}$ of Follin-Ciocalteu's reagent then $5 \mathrm{ml}$ of distilled water and $1.5 \mathrm{ml}$ of sodium bicarbonate $(\mathrm{Na} 2 \mathrm{CO} 3)$ solution $(\mathrm{w} / \mathrm{v}=20 \%)$ were added. The volume was made up with distilled water.

During oxidation of phenolic compounds, phosphormolybdic and phosphortungstic acid, contained in the Folin-Ciocalteu's reagent, were reduced to bluecolored molybdenum and tungsten oxides. After two hours, the absorbance of blue coloration was measured at absorbance $765 \mathrm{~nm}$ against a blank sample. The measurements were compared to standard curve of prepared gallic acid solutions (concentration range of 100 to $500 \mathrm{ppm}$ ) and expressed as milligram of gallic acid equivalent per $100 \mathrm{~g} \pm$ S.D. All measurements were performed in triplicate.

\subsection{Fourier transform infrared spectroscopy (FTIR) analysis}

Perkin Elmer Universal Attenuated Total Reflectance (ATR) sampling accessory was used to obtain the FTIR spectrum of breadfruit leaves. The sample of leaves was in the form of powder. Data collection and processing were tested by Spectrum version 6.2.0.0055 software.

\section{Results and Discussion}

\subsection{Antioxidant capacity and total phenolic content}

Antioxidants have the ability to prevent free radical tissue damage by inhibiting free radicals formation, scavenging them and promoting their decomposition. Phenolic components are the primary antioxidants to deliver antioxidant ability and protection against the attack of harmful reactive oxygen species. Total phenolic contents in plants might affect the antioxidant capacity [12].

Total phenol content (TPC) of the fresh breadfruit leaves was quantified from a calibration curve $(\mathrm{y}=$ $0.0053 \mathrm{x}-0.487)$ of gallic acid and expressed as $\mathrm{mg} / \mathrm{g}$. Total phenolic content in fresh breadfruit leaves (144.16 $\mathrm{mg} / \mathrm{g} \pm 17.98$ ) was comparable to those of green tea [13]. This suggests that breadfruit leaves extracts is a potential beverage and its consumption can provide phenolic contents to promote health.

Aging and different chronic diseases including diabetes and cardiovascular diseases could be caused by oxidative stress. The percentage DPPH radicalscavenging inhibition of fresh breadfruit leaves was $63.88 \% \pm 1.87$. This finding was consistent with antioxidant activity in fresh ginger reported by [14] $\mathrm{Li}$ et al. (2016). The result indicates that the leaf extracts are capable of scavenging the free radicals and prevent the initiation of free radicals by stabilizing them to participate in any deleterious reactions.

\subsection{FTIR analysis}

The FTIR spectrum of fresh breadfruit leaves is shown in Figure 1. The FTIR Spectrum of breadfruit leaves indicate the presence of primary alcohol $\mathrm{CO}$ stretching (1037.74 cm-1 region), alkene $\mathrm{C}=\mathrm{C}(1604.91$ cm-1 region), alkyne (2160.24 cm-1 region), alkane $\mathrm{CH}$ stretching (2918.13 -2850.09 cm-1 region) and $\mathrm{OH}$ bonding group (3264.15 cm-1 region), typical characteristic of tea leaves polysaccharides [15]. The results suggest that the breadfruit leaves preventing the risk of diabetes as tea polysaccharides is a bioactive substance possess antioxidant and immunological activities [16]. 
High intensity of bands found at $1037.74 \mathrm{~cm}-1$ for indicated the presence of phenolic compound in breadfruit leaves. This indicates that breadfruit leaves are potentially served as a healthy diet for human as phenolic compounds exhibit a wide range of biological and physiological functions, such as anti-allergenic, antiinflammatory, anti-microbial and antioxidant activities [17][18]. The presence of $\mathrm{OH}$ group indicates antioxidant capacity of breadfruit leaves to deactivate free radicals as glucose itself could react with hydrogen peroxide in the presence of iron and copper ions to form hydroxyl radical [19].

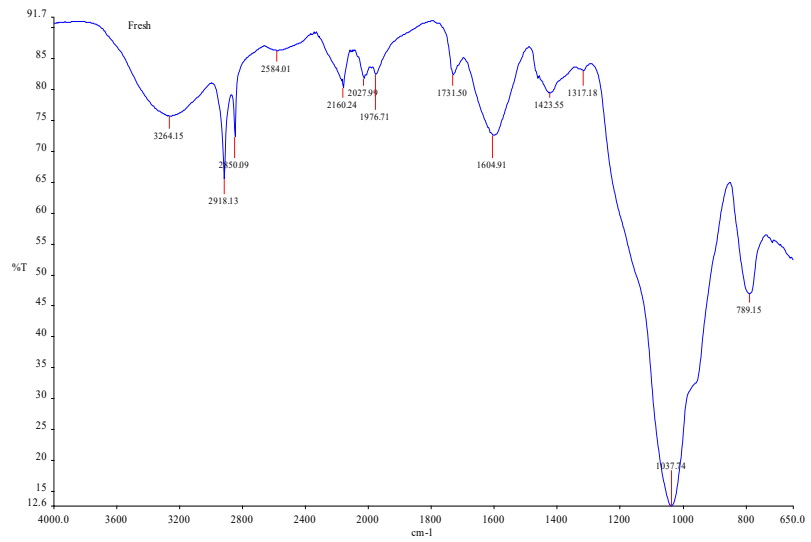

Fig. 1. FTIR spectrum of fresh breadfruit leaves.

\section{Summary}

Diabetes affects about $5 \%$ of the global population [20]. The outcome of diabetes is determined, to a large extent, by patients'adherence to medication and lifestyle changes, and the maintaining of adherence to oral antidiabetic medications has been one of the important steps in reaching long-term glycemic control. Management of diabetes without any side effects is still a challenge to the medical system. A growing interest of people on the antioxidant research on plants due to their possible uses as natural additives to replace synthetic ones. The results of the present study showed that the breadfruit leaves extracts exhibited potent antioxidant activity. Further investigation of the anti-glucosidase activities of phenolic-rich extracts from Artocarpus altilis leaves in mitigating diabetes is required

The authors acknowledge the financial support received from the Short Term Grant of Universiti Perlis Malaysia, the research facilities of the Institute of Sustainable Agrotechnology (INSAT) and Faculty of Engineering Technology, UniMAP.

\section{References}

[1] B. Halliwell, J. Gutteridge, Free radicals in biology and medicine, (Fifth ed.)Oxford University Press, Oxford USA (2015)

[2] A. Gioxari, D.A.A. Kogiannou, N. Kalogeropoulos, A.C. Kaliora, Phenolic compounds: bioavailability and health effects, B. Caballero, P.M. Finglas, F. Toldrá (Eds.), Encyclopedia of Food and Health, Vol. 1, Elsevier Science, Kidlington, United Kingdom, UK, 339-345 (2016)

[3] S. Kumar, A.K. Pandey, Chemistry and biological activities of flavonoids: an overview, Sci. World J., pp. 162750 (2013)

[4] Kameswara Rao B, Kesavulu MM, Apparao C, Evaluation of hypoglycemic effect of Momordica cymbalaria fruit in alloxandiabetic rats. Fitoterapia, Vol. 74, pp. 7-13 (2003)

[5] M. Kopjar, M. Tadic, Phenolic content and antioxidant activity of green, yellow, and black tea leaves, Chem. Biol. Techn. Agric., Vol. 2, no.1, pp. 1-6 (2015)

[6] A.M.P. Jones, R. Baker, D. Ragone, S.J. Murch, Identification of pro-vitamin A carotenoid-rich cultivars of breadfruit (Artocarpus, Moraceae), J. Food Compost. Anal., Vol. 31, pp. 51-61 (2013)

[7] C.A. Lans, Enthnomedicines used in Trinidad and Tobago for urinary problems and diabetes mellitus, J. Ethnobiol. Ethnomed., Vol. 2, 45 (2006)

[8] D.D. Ramdath, C.L.R. Issacs, S. Teelucksingh, S.M.T. Wolever, Glycaemic index of selected staples commonly eaten in the Caribbean and the effects of boiling $v$. crushing, Br. J. Nutr., Vol. 91, pp. 971-977 (2004)

[9] P. Cos, L.Y. Ying , M. Calomme , J.H. Hu, V.P.K.B. Cimanga, L. Pieters, A.J. Vlietinck, D.V. Berghe, Structure activity relationships and classification of flavonoids as inhibitors of xanthine oxidase and superoxide scavengers, J. Nat. Prod., Vol. 61, pp. 71-76 (1998)

[10] S. Abbas, M.Wink, Epigallocatechin gallate from green tea (Camellia sinensis) increases lifespan and stress resistance in Caenorhabditis elegans. Planta Medica, Vol. 75, pp. 216-221 (2009) 
[11] V.L. Singleton, J.A. Rossi, Colorimetry of Total Phenolics with PhosphomolybdicPhosphotungstic Acid Reagents, Am. J. Enol. Vitic., pp. 144-158 (1965)

[12] Duda, S.C. L.A. Mărghitaş, D. Dezmirean, M. Duda, R. Mărgăoan, O. Bobiş, Changes in major bioactive compounds with antioxidant activity of Agastache foeniculum, Lavandula angustifolia, Melissa officinalis and Nepeta cataria: Effect of harvest time and plant species. Ind Crops Prod., Vol. 77, pp. 499-507 (2015)

[13] U.J. Unachukwu, S. Ahmed, A. Kavalier, J.T. Lyles, E.J. Kennelly, White and green teas (Camellia sinensis var. sinensis): variation in phenolic, methylxan-thine, and antioxidant profiles. J. Food Sci., Vol. 75, pp. 541-548 (2010)

[14] Li, Y. Hong, Y. Han, Y. Wan, L. Xia, Chemical characterization and antioxidant activities comparison infresh, dried, stir-frying and carbonized ginger, J. Chromatogr. B, Vol. 1011, pp. 223-232 (2016)

[15] Y.F. Wang, F.F. Mao, X.L. Wei, Characterization and antioxidant activities of polysaccharides from leaves, flowers and seeds of green tea, Carbohydr. Polym., Vol. 88, pp. 146-153 (2012)
[16] J.J. Yang, B. Chen, G. Yan, Pharmacological evaluation of tea polysaccharides with antioxidant activity in gastric cancer mice, Carbohydr. Polym., Vol. 90, no. 2, pp. 943-947 (2012)

[17] N. Balasundram, K. Sundram, S. Samman, Phenolic compounds in plants and agriindustrial by-products: Antioxidant activity, occurrence, and potential uses, Food Chem., Vol. 99, no. 1, pp. 191-203 (2006)

[18] M. Claudine, M. Andrzej, S. Augustin, Polyphenols and prevention of cardiovascular diseases, Curr. Opin. Lipidol, Vol. 16, no. 1,pp. 77-84 (2005)

[19] M. Valko, C.J. Rhodes, J. Moncol, M. Izakovic, M. Mazur, Free radicals, metals and antioxidants in oxidative stress-induced cancer, Chem Biol Interact, Vol. 160, pp. 1-40 (2006)

[20] R. Chakraborty, R. Rajagopalan, Diabetes and insulin resistance associated disorders: disease and the therapy. Curr. Sci. India, Vol. 83: 15331538 (2002) 